with ReadMI technology with residents who receive the usual and customary MI training. ReadMI has the potential to transform MI training, because the prospective applications of ReadMI extend far beyond substance misuse detection and intervention to include chronic disease management. ReadMI will likely improve health care quality by better equipping physicians as decision support agents in their efforts to facilitate patients' health-related behavior change.

\section{Miteshkumar M. Vasoya, BS}

Graduate Student, Department of Computer Science and Engineering, Wright State University

\section{Ashutosh Shivakumar, MS}

Graduate Student, Department of Computer Science and Engineering, Wright State University

\section{Sowmya Pappu, MS}

Graduate Student, Department of Computer Science and Engineering, Wright State University

\section{Cara P. Murphy, BA}

Medical Student, Wright State University Boonshoft School of Medicine

\section{Yong Pei, PhD}

Associate Professor, Department of Computer Science and Engineering, Wright State University

\section{Dean A. Bricker, MD}

Associate Professor, Department of Internal Medicine, Wright State University Boonshoft School of Medicine

\section{Josephine F. Wilson, DDS, PhD}

Professor, Department of Population and Public Health Sciences, Wright State University Boonshoft School of Medicine

\section{Angie Castle, MA}

SBIRT Trainer, Department of Family Medicine, Wright State University Boonshoft School of Medicine

\section{Paul J. Hershberger, PhD}

Professor, Department of Family Medicine, Wright State University Boonshoft School of Medicine

Corresponding author: Paul J. Hershberger, PhD, Wright State University Boonshoft School of Medicine, Department of Family Medicine, 725 University Boulevard, Dayton, OH 45435, 937.245.7223, fax 937.245.7931, paul.hershberger@wright.edu

\section{"Clinical Teaching is Like Improv Because..." A Faculty Development Strategy}

\section{Setting and Problem}

The opportunity to teach is often cited as an important reason physicians become involved in graduate medical education (GME). As of July 1, 2019, the Accreditation Council for Graduate Medical Education Common Program Requirements will require faculty members to pursue formal faculty development designed to enhance their skills, including those as teachers. Research has demonstrated that while expert teachers often appear to teach (or perform) without a lesson plan, it is not unplanned. Expert clinical teachers take cues from the patient, learners, setting, and time available to decide which educational path to pursue. It's an interactive process determined by the responses of the learners (audience)-adapting the content and strategies to best meet learners' needs-a skillset that is commonly associated with improv.

\section{Intervention}

Improv is increasingly used in medical education as an approach to improve communication skills. But it has had limited application as a faculty development strategy focused on clinical teaching. Applied Improv, like clinical teaching, has key principles and rules ranging from "Be present" and "Respect your Partner" to "Yes and ...." When these skills are applied to a "teaching scene," they yield faculty development exercises that are quick, practical, timely, and consistent with key principles of well-being (purpose and meaning as teacher, competence, relationship, autonomy). Our sessions begin, just as in improv, with at least one warmup exercise. For example, participants shout out responses to an exercise called "Go with the possibility that clinical teaching is like improv because ...." This exercise requires participants to warm up cognitively by identifying commonalities. The "Teacher's Pet Peeves" dyad warm-up exercise starts with one participant stating a teaching "peeve" (Residents just don't read anything in depth-only what's on their app). The

DOI: http://dx.doi.org/10.4300/JGME-D-18-00870.1 
listener then has 60 seconds to reframe the peeve into a positive by connecting the emotion to a value (Clearly it is important to you that residents understand the "why" along with the "what" we do as physicians). These exercises require the teacher to be present, cognitively agile, and connect emotionally, thereby strengthening interpersonal connections and relationships. Various teaching scenes are then established by asking the audience to define "who," "what," and "where" questions, or scenarios can be provided. This gives participants the opportunity to apply the improv skills of "Agree," "Yes and ...," and "Make Statements" (not questions disguised as statements, thereby showing respect and adding value to the interaction) as clinical teachers. Depending on time at the initial session, the teaching scenes can start (or continue to occur) at subsequent sessions. All sessions close with a large group debriefing discussion to identify benefits and barriers of using improv skills as teachers.

\section{Outcomes to Date}

This interactive and LOL (laugh-out-loud) approach to faculty development has been presented locally and nationally to rave reviews. Evaluations from a regional and a national meeting $(\mathrm{N}=50)$ utilized a 4-point scale (1, strongly agree/yes definitely, to 4 , strongly disagree/ no definitely not) with mean responses for all items less than 1.2. The items included: The session "increased my repertoire of teaching strategies"; The session made me "be truly present-attentively listen, focused on nownot what I'm going to say next"; The session made me recognize that "improv utilizes many of the same skills associated with expert teaching" and I would "recommend this session to other medical educators." The item "Session rocked/was a mic drop!" was rated strongly agree by over $85 \%$ of respondents (remainder agree). Long-term follow-up using local participants' teaching evaluations baseline/post is anticipated.

\section{Deborah Simpson, $\mathrm{PhD}$}

Medical Education Program Director, Advocate

Aurora Health

Adjunct Clinical Professor of Family Medicine \&

Community Health, University of Wisconsin School of Medicine and Public Health

Adjunct Clinical Professor of Family \& Community

Medicine, Medical College of Wisconsin

Deputy Editor, Journal of Graduate Medical Education

\section{Will Lehmann, MD}

Chair and Family Medicine Residency Program

Director, Department of Family Medicine, Aurora

Legacy, part of Advocate Aurora Health

Clinic Adjunct Assistant Professor of Family
Medicine, University of Wisconsin School of Medicine and Public Health

\section{Jacob Bidwell, MD}

Designated Institutional Official, Aurora Health Care

Graduate Medical Education, part of Advocate

Aurora Health

Clinical Adjunct Associate Professor of Family

Medicine, University of Wisconsin School of

Medicine and Public Health

Kjersti Knox, MD

Director, Training in Urban Medicine and Public Health (TRIUMPH) Program, and Clinical Adjunct Associate Professor of Family Medicine, University of Wisconsin School of Medicine and Public Health

\section{Carla Kelly, DO, MMM}

Chair and Residency Program Director, Department of Obstetrics and Gynecology, Aurora Legacy, a part of Advocate Aurora Health

\section{Mark Robinson, DO}

Director of Osteopathic Education, Aurora Health

Care Medical Group

Clinical Assistant Professor of Family Medicine, University of Wisconsin School of Medicine and Public Health

Corresponding author: Deborah Simpson, $\mathrm{PhD}$, Aurora Health Care, Academic Affairs, 1020 North 12th Street, Suite 5120, Milwaukee, WI 53233, 414.219.7270, fax 414.385.1582, deb.simpson@aurora.org

\section{All GME Is Local: A Novel Approach to GME Governance in a Consortium Model}

\section{Setting and Problem}

In a newly formed graduate medical education (GME) consortium model supporting a complex academic

DOI: http://dx.doi.org/10.4300/JGME-D-18-00909.1 